\title{
Measurement and traceability of torque on large mechanical drives
}

\author{
Beaho Guy \\ HBM Darmstadt Germany, \\ guy.beaho@hbm.com
}

\begin{abstract}
Considering the exhaustive torque measurement possibilities, the method including a torque transducer calibrated from the manufacturing site, with a given accuracy which refers to a documented unbroken chain of comparisons relating this torque transducer to the primary standard, ensures its traceability. Precision measurements are essential to determine the efficiency and therefore meet the strict environmental regulations for marine engines.
\end{abstract}

Key words: high nominal torque, power, efficiency, calibration, traceability, primary standard.

The power and efficiency of rotating machines and drive systems in both test benches and the monitoring systems are always critical issues (see Fig. 1).

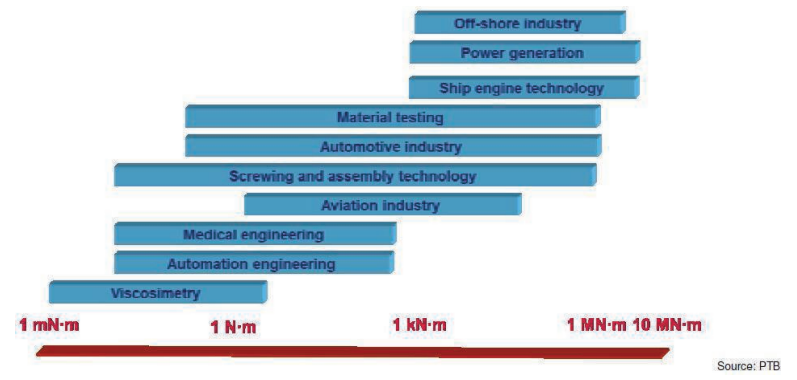

Fig. 1. Industrial applications and nominal torques

Their optimization based on the highly accurate and reliable measurement of the torque, besides enabling significant energy savings, fits to the steadily increasing requirements of the international regulation, especially for marine engines with high nominal torque [1].

The drive power is simply calculated, from this accurate measure of the torque $M$ between the generator and the drive side in the rotating mechanism and the angular velocity $\omega$, with the formula (1):

$P=2 \pi * \omega * \mathrm{M}$

The accurate torque information makes possible to precisely control the mechanical drive system. Therefore the combustion engine (e.g. multi-fuel or gas engines) are monitored to operate within their optimal working window, which helps to avoid the occurrence of knocking, misfiring, overloading, and reduces fuel consumption as well [1].

Torque can be measured directly or indirectly:

\section{Direct torque measurement}

The direct torque measurement uses an inline torque transducer as an integrated part of the drive shaft (see Fig. 2). The torque transducer is already calibrated at the manufacturer's site using appropriate calibration machines. The transducer can be easily installed, removed, replaced and recalibrated.

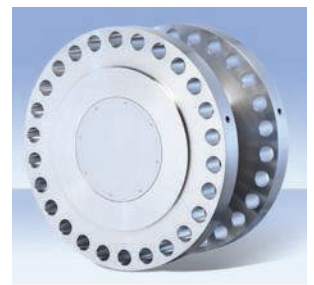

Fig. 2. Torque flange sensor HBM T4OMAR

\section{Indirect torque measurement}

Indirect torque measurement on a cylindrical shaft applies via a measure of torque-related parameter and subsequent calculation.

a) Measure of the strain on the input shaft surface. Strain gauges are therefore glued directly onto the shaft and then connected into a measuring bridge. The measuring bridge excitation voltage and the measurement signal are transferred in both cases contactless.

b) Another method for determining torque on a cylindrical shaft is through measurement of the torsion angle.

Both methods offer some advantages, as retrofit of existing systems. Depending on the installation quality and the components used, the torque value to be subsequently calculated might have a relatively high uncertainty because of the tolerances (see Tab. 1) which finally lead to a relatively significant measurement uncertainty 
Tab. 1: Comparison of tolerances between direct and indirect method

\begin{tabular}{|c|c|c|}
\hline $\begin{array}{c}\text { Input } \\
\text { variables }\end{array}$ & $\begin{array}{l}\text { Tolerance of e.g. } \\
\text { on site strain } \\
\text { gage installation }\end{array}$ & $\begin{array}{l}\text { Tolerance of } \\
\text { torque } \\
\text { transducer }\end{array}$ \\
\hline $\begin{array}{l}\text { Youngs } \\
\text { modulus }\end{array}$ & $2 \ldots 5 \%$ & $\sim 0 \%$ \\
\hline $\mathrm{k}$ - factor & $\sim 1 \%$ & $\sim 0 \%$ \\
\hline Shaft geometry & $\sim 1 \%$ & $\sim 0 \%$ \\
\hline $\begin{array}{l}\text { Strain gage } \\
\text { positioning }\end{array}$ & $1 \ldots 5 \%$ & $\sim 0 \%$ \\
\hline $\begin{array}{l}\text { Temperature } \\
\text { impact }\end{array}$ & $2 \ldots 5 \%$ & $\sim 0,1 \%$ \\
\hline Sum & $\begin{array}{l}5 \ldots 7 \% \text {, not } \\
\text { detectable }\end{array}$ & $\begin{array}{c}\sim 0,2 \ldots 0,3 \% \\
\text { detectable }\end{array}$ \\
\hline
\end{tabular}

\section{Calibration and Traceability}

To ensure the precision of the drive power or the efficiency which are essential to meet the strict environmental regulations in the marine engine industry, next to the measurement of the high torque, the calibrations and traceability of this physical quantity are increasingly coming into focus [2]. Basically, the techniques used in torque calibration are subdivided in lever-armmass system and reference transducer.

- lever-arm-mass systems: a precisely defined torque is generated when the weight force of calibrated masses acts on the test specimen by means of a lever arm of known length [4].

- The second technique in torque calibration is using a force reference transducer with a lever arm [3].

- The third principle is a torque reference transducer which provides the reference value. Systems with torque reference transducers can use any mechanism to generate the torque which is then measured with the torque reference transducer [2] [3].

\section{HBM's New Torque Calibration Machine}

According to the reference standard, this new calibration machine (see Fig. 3) combines features of the following two methods used for torque calibration: The lever-arm-mass systems and the method including a torque reference transducer which provides the reference torque. As a reference transducer modified $\mathrm{T} 10 \mathrm{FH} / 150$ $\mathrm{kN} \cdot \mathrm{m}$ and $\mathrm{T} 10 \mathrm{FH} / 400 \mathrm{kN} \cdot \mathrm{m}$ torque transducers were chosen. Due to the two precision reference transducers, a measurement uncertainty of $0.1 \%$ could be achieved.

The main contribution to the remarkable uncertainty results comes from the documented unbroken chain of comparisons relating these torque transducers to the reference transducer of the German National Standard (see traceability pyramid, Fig. 4).

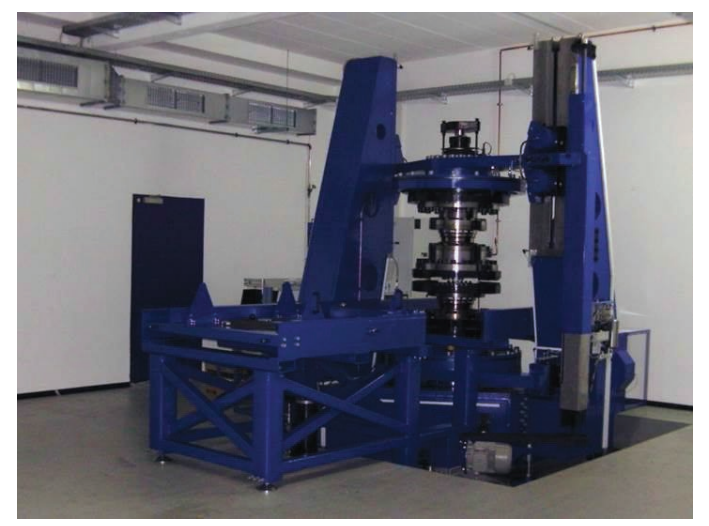

Fig. 3. $400 \mathrm{KN} \cdot \mathrm{m}$ Calibration Machine at HBM Darmstadt

The measurement uncertainty of the German National standard, the highest rank calibration machine with $1.1 \mathrm{MN} \cdot \mathrm{m}$ also referred as "torque standard machines" owned by the PTB, to which this new $400 \mathrm{kN} \cdot \mathrm{m}$ calibration machine is traced back to, is $0.08 \%$.

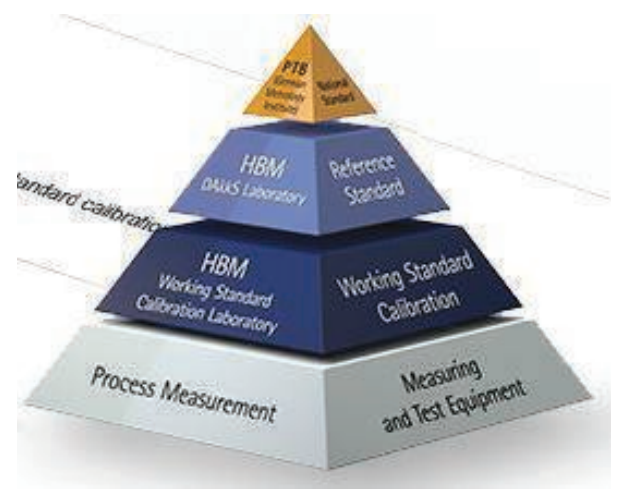

Fig. 4. Traceability pyramid of the torque

This precision related to the torque sensor enables to measure the torque and therefore to calculate the power and the efficiency with accuracy at least 10 times better than the current environmental regulations requirement of the marine industry.

\section{References}

[1] K. Weissbrodt, Direct torque measurement on large drives with very small tolerances, Paper Hottinger Baldwin Messtechnik GmbH (2011)

[2] H. Frais, L. Lioba, D. Röske, Development of a New 400KN.m Torque Calibration Machine, Paper, Hottinger Baldwin Messtechnik $\mathrm{GmbH}$ (2015)

[3] R. Schicker and G. Wegener, Measuring Torque Correctly. Bielefeld: Hottinger Baldwin Messtechnik GmbH. (2002)

[4] Davis, F.A. The 1st UK National Standard Static Torque Calibration Machine-New Design Concepts Lead The way. Measurement Science Conference in Anaheim, USA. (2002) 